\title{
Is Mississippi's Prescription-only Precursor Control Law a Prescription to Decrease the Production and Raise the Price of Methamphetamine?
}

\author{
Scott Cunningham, Keith Finlay, and Charles Stoecker*
}

May 14, 2015

\begin{abstract}
Background: In 2010, Mississippi became the second state to require a prescription to purchase pseudoephedrine-based medications. Proponents of "prescription-only" laws argue that they are necessary to disrupt methamphetamine markets, but critics note the costs to legal consumers of cold medications may offset some of the laws' intended benefits.

Objective: We evaluated the effect of prescription-only restrictions for methamphetamine precursors on state-level methamphetamine lab seizures and methamphetamine prices.

Methods: We used a synthetic control approach to create a control state comparable to Mississippi and then used permutation testing to determine if the resulting difference was statistically significant.
\end{abstract}

Results: We found that Mississippi's prescription-only law removed 2,637 small methamphetamine labs in the two years after the law became effective, which represents a $77 \%$ reduction in small labs relative to the synthetic counterfactual. We found no evidence that the law impacted methamphetamine prices.

${ }^{*}$ Cunningham: Department of Economics, Baylor University, Waco, TX. Finlay: Department of Economics, Tulane University, New Orleans, LA. Stoecker: Department of Global Health Systems and Development, Tulane University School of Public Health and Tropical Medicine, New Orleans, LA. cfstoecker@tulane.edu (corresponding author) We thank the National Science Foundation (award SMA-1004569), the Robert Wood Johnson Foundation (award 70509), and the Tulane Research Enhancement Fund for support. 
Conclusion: We conclude that while prescription-only laws can reduce the number of domestic small methamphetamine labs in operation, methamphetamine availability is unlikely to be materially impacted.

Keywords: illegal drugs, demand, methamphetamine laboratories, synthetic control 


\section{Introduction}

Methamphetamine (meth) use is a widespread problem with an estimated 595,000 users in 2013, up 69\% from 2010 (though below the high in 2006) ([SAMHSA] Substance Abuse and Mental Health Services Administration, 2014). The number of users has remained steady in the last few years ([US DEA] United States Drug Enforcement Administration, 2013). Its use disproportionately affects vulnerable populations (Gonzales et al., 2010; Kushel et al., 2005; Chew Ng et al., 2012) and is frequently associated with other risky behaviors (Shaw et al., 2008).

Meth, and d-methamphetamine in particular, production depends on access to scarce inputs, such as pseudoephedrine and ephedrine. Traditionally drug policy has tended to intervene into meth output markets by disrupting domestic access to these inputs.

Due to domestic meth market rebounding after several major federal interventions in the 1990s, states throughout the early 21st century experimented with a variety of over-the-counter regulations to impede illegal use of pseudoephedrine (PSE) in the manufacturing of meth. In 2006, the federal Combat Methamphetamine Epidemic Act of 2005 (CMEA) went into effect and led to a large disruption in domestic meth markets (Dobkin et al., 2014; Cunningham and Finlay, 2015). While initially followed by promising declines in meth synthesis in domestic labs, pseudoephedrine and ephedrine import restrictions in Mexico in 2008 and 2009 led to rebounds in domestic meth lab activity ([US NDIC] United States National Drug Intelligence Center, 2010). Domestic production and small lab activity has continued, despite restricted access to key precursor inputs following the CMEA. This is due, in part, to domestic meth producers ability to circumvent regulations by relying on organized pseudoephedrine purchasing rings, or "smurfing" ([US NDIC] United States National Drug Intelligence Center, 2010). Members of smurfing groups make multiple small purchases of precursors so that no single transaction exceeds the legal limit.

The steady increase in domestic meth activity has led to continual policy experimentation at the state level to control access to chemical precursors (Dobkin et al., 2014; Cunningham and Finlay, 2015). The two most commonly proposed regulatory policies at the state level are computerized databases listing all pseudoephedrine purchases across all retail distributors and laws requiring a doctor's prescription for dispensation.

Two states have enacted "prescription-only" laws for meth precursors: Oregon in 2005 and 
Mississippi in 2010. While most states classify meth precursors as Schedule V substances that can be obtained over the counter, Mississippi and Oregon have classified these drugs as Schedule III substances which require a prescription for purchase. Oregon's prescription-only law went into effect within four months of the CMEA, making separate identification of the impacts of the two policies difficult. Additionally, Cunningham et al. (2012) have shown lab seizures had decreased prior to the prescription requirement making sizable additional decreases infeasible. In February 2010, Mississippi enacted a prescription-only law that became effective in July 2010. As this policy was enacted several years after the federal CMEA and in a state where small lab production was relatively common it is suitable for a quasi-experimental analysis.

Previous work has analyzed changes in trends in meth lab seizures in Mississippi coincident with the prescription requirement (Cunningham et al., 2012). In this paper we expand on this prior work by using a synthetic control method for data analysis. It is particularly suited for application to this comparative case study as it constructs a synthetic control group algorithmically, rather than relying on a pre-post comparison within Mississippi. Statistical inference is then performed with permutation testing on effects in the treatment series compared to control series.

Our second principal contribution is an examination of the impacts of prescription requirements for precursors on methamphetamine prices. As representative data on meth availability does not exist, prices can serve as a proxy for drug availability. Our previous work (Cunningham and Finlay, 2015) found demand for meth was inelastic, even in the face of dramatic price changes. A particularly effective 1995 federal restriction on ephedrine distribution caused methamphetamine prices to triple over their trend levels (Dobkin and Nicosia, 2009). Since demand for meth is relatively inelastic, a decrease in availability of the drug will be detectable in the price data.

In this paper we use a synthetic control approach to examine the impact of Mississippi's prescription-only regulation of meth precursors on meth lab seizures and meth prices. 


\section{Methods}

\subsection{Discussion of datasets}

For ideal identification of the impact of the law on the number of meth labs, we would like to have counts of operating meth labs. As meth production is illegal, we instead used counts of meth lab seizures from the National Clandestine Laboratory Register (NCLR) maintained by the DEA's El Paso Intelligence Center (EPIC). We applied for and were granted access to the complete NCLR records for January 2000 to December 2012 using a Freedom of Information Act request. We started our analysis in 2007 to avoid any contaminating effects of the federal CMEA. These data were obtained at the incident level and contain detailed geographic information (including county and street address), lab capacity, seizure date, and lab type (anhydrous ammonia, tablet extraction, meth, etc.). We used lab type to limit our analysis to meth labs, and seizure date and location to aggregate data to the state by month cell for analysis. We restricted our analysis to labs with capacities under 2 ounces, since we expected small labs to be most affected by this retail-level requirement for precursor purchase.

Figure 1 plots raw counts of small meth lab seizures for Mississippi compared to the rest of the country. Nationwide, the number of small meth labs seized has risen since the post-CMEA trough of 2007, possibly as a response to the Mexican ban of pseudoephedrine importation ([US NDIC] United States National Drug Intelligence Center, 2010). Meth lab seizures in Mississippi rose contemporaneously with national trends until shortly before the law became effective on July 2010. This was followed by a sharp decline in Mississippi seizures during the rest of 2010. The fact that this dramatic decline began after the enactment date may be an indication that pharmacies or other actors were experiencing the impact of the prescription laws in anticipation of the effective date. Our objective was to investigate this sharp decline, and thus we used both the enactment and effective dates as the break-point. We present analysis based on the effective date.

We do not observe meth use directly, and in the case of Mississippi, we do not observe it indirectly either. Mississippi's treatment data reported to Treatment Episode Data Set (TEDS), for instance, was incomplete for most of 2010 thus making it inappropriate for this analysis. And, while hospitalization inpatients and emergency room visits produce toxicology reports on patient drug screens that would be useful for this analysis, Mississippi does not submit its data to 
the Healthcare Cost and Utilization Project (HCUP). Without data on usage patterns, we turned instead to price data to look for evidence of impact on supply patterns. If the intervention had successfully limited meth availability in a meaningful way, we should have detected increases in price that may have limited availability of the drug on the margin.

We modeled quarterly state-level retail meth price using data from the DEA's System to Retrieve Information from Drug Evidence (STRIDE). STRIDE is a database of all drug exhibits sent by local and federal law enforcement agencies to the DEA for analysis. While not a representative sample of drugs in the US, it is the universe of all evidence seen by DEA labs and includes domestic and foreign sourced drugs, as well. Whereas NCLR measures seizures only, STRIDE contains drug exhibits from undercover purchases in addition to seizures from arrests. We used information from each drug exhibit to construct estimates of the inflation-adjusted price of a pure gram of meth for each state. We used a previously published hierarchical model (Arkes et al., 2004) which first predicts expected purity, based on the median purity of a gram of meth exhibit from the distribution of meth exhibits from each state and quarter cell, and then uses that prediction to derive price. We limited our price predictions to retail transactions by excluding transactions where either party had more than 100 grams of meth. We then aggregated number of meth labs seized and meth price to state by quarter cells for analysis. We explored a specification that used data at the month level, but were unable to obtain good model fits due to cells with missing data.

\subsection{Synthetic control}

The synthetic control estimator (Abadie and Gardeazabal, 2003; Abadie et al., 2010) constructs a control time series by matching pre-trends in the treatment observation to a constructed control observation that consists of a weighted average from several potential control observations. This method is designed to evaluate interventions where there is only one observation in the treatment group, and thus is especially suited to analyzing comparative case-studies. Unlike ad hoc selection of control units, the synthetic control estimator selects the weights of the control unit algorithmically to remove subjective researcher bias. The synthetic control algorithm finds weights for each unit in the potential pool of controls by minimizing the mean-squared difference in the control variables between the treatment and the synthetic controls. Weights are constrained to be non- 
negative and sum to unity. All analysis was done using synth for Stata 13 (Abadie et al., 2011).

Given the importance of correctly modeling the unobserved counterfactual time path of Mississippi outcomes post-treatment using comparable state units for controls, special attention was given to the dynamics leading up to the date prescription-only requirements became effective in Mississippi. We did not rule out any state as a possible match because we did not want to introduce subjective researcher bias related to the selection of our counterfactual. We also wanted to have as large a pool as possible to improve precision in our falsification exercise. In our exploration of lab seizures we estimated a vector of state-specific weights which minimized the mean-squared distance between Mississippi and the synthetic control state for meth lab seizures in the 3 months before the prescription-only law, having legalized Medical marijuana, cigarette taxes, state unemployment rates, number of people on the Supplemental Nutrition Assistance Program, and the population between ages 15 and 49. In our investigation of the impact of these laws on meth prices, we used several additional variables to achieve balance. We used meth prices in 2009 quarter 4, 2009 quarter 2, 2008 quarter 4, 2008 quarter 1, and the average of meth prices in 2007 quarters 1 and 2.

Statistical inference with synthetic control was performed using permutation testing (Abadie et al., 2010). Each potential control observation was recast as the treatment observation for a placebo test and weights were assigned to the remaining observations in potential pool of controls to construct a placebo synthetic control for the placebo treatment. For each of these placebo tests, we tracked the difference between the placebo and the synthetic control calculated specifically to match that placebo. Then the effect we calculated for the actual treatment group was compared to each of the placebo effects. If the actual treatment effect was large compared to the placebo effects, we concluded that the synthetic control point estimate was statistically significant. In our application we had $49^{1}$ potential control observations which allowed us to determine statistical significance at the $2 \%, 4 \%, 6 \%$, etc. levels.

\footnotetext{
${ }^{1}$ We included 48 other states and the District of Columbia. We excluded Oregon since it already had an active prescription requirement.
} 


\section{Results}

The quality of the match on observables is reported in Table 2. Column 1 shows the average of each variable we used to construct the synthetic control weights. Column 2 shows these same variables for Mississippi. And Column 3 shows the weighted average of each of these control variables after the weights were constructed for the synthetic control. ${ }^{2}$ A good match would have similar values in Columns 2 and 3. The synthetic state was similar to Mississippi with regards to each of the matching variables. The quality of match for meth lab seizures over time is shown in the top panel of Figure 2. The dashed vertical line indicates the enactment date for Mississippi's law requiring prescriptions for purchase of pseudoephedrine-based medications. The trajectories in meth lab seizures between Mississippi and the synthetic control were fairly close during the pre-intervention period.

Shortly after the prescription requirement was enacted in Mississippi, the two lines diverged, with meth lab seizures going down in Mississippi relative to the synthetic control. The total cumulative effect of the law after two years can be read from the cumulative vertical distances between the two lines. During the post-intervention period there were 766 small lab seizures in Mississippi and 3,403 small lab seizures in the synthetic control state. This cumulative distance indicates there were 2,637 fewer meth lab seizures in Mississippi due to the enactment of the prescription-only law in the subsequent two years relative to a synthetic counterfactual.

The second panel in Figure 2 plots the difference in each month between a treatment (or placebo treatment) state and its associated synthetic control state for Mississippi (bold line) and all other states. This figure provides insight into whether the estimated causal effects in the top panel are simply an artifact of the model chosen by applying the same model to all states in our sample. Since the intervention occurred in Mississippi, the other lines represent estimated causal effects from a placebo assignment and thereby allowed us to examine the performance of our model when used to estimate a non-existent treatment effect. Mississippi showed a larger decrease in meth lab seizures compared to its control than any other of the placebo treatment states after the law change as well as a very good fit pre-treatment relative to the model's performance posttreatment. The differences for the placebo treatment states were clustered around the zero line

\footnotetext{
${ }^{2}$ The weights of states that most closely matched trends in meth lab seizures in Mississippi were Kentucky (0.199), Tennessee (0.292), District of Columbia (0.27), Missouri (0.237) and Alaska (0.001).
} 
indicating no difference between each placebo treatment state and its associated synthetic control state. Our permutation test indicated that Mississippi saw a larger impact of the law change than the other 49 placebo states, so we conclude our results are significant at the $2 \%$ level. ${ }^{3}$

The variables used for matching in our average meth price model are shown in Table 2. Note that the information presented represent mean values for each variable. We constructed a synthetic control which exhibited similar pre-treatment dynamics in meth prices to the treatment state. The impact of the prescription requirement for obtaining precursors on average meth price in the state is shown in Figure 4. The top panel compares meth price trends in Mississippi to the synthetic control state. The price trends are noisier in Mississippi in the pre-period, and no clear difference between treatment and control is apparent in the post-period. This is borne out by the permutation test performed in the second panel of Figure 4. We found no significant impacts of the prescription requirement for precursors on meth prices.

\section{Discussion}

We took advantage of Mississippi's 2010 legislation and estimated a synthetic control model to examine the net effect on meth markets. First, we found that Mississippi's 2010 prescriptiononly law for meth precursors had a strong negative impact on meth lab seizures in the two years following enactment. We found no impact of these seizures on prices for meth in Mississippi. Taken together, these results suggest that the effect of the law was primarily concentrated on Mississippi manufacturers of meth who are a small part of total supply. Thus, with meth still as available in the state with or without prescription-only requirements for precursors, the law appears to have failed to raise prices and therefore may have had no effects on meth use or costs associated with addiction.

Our findings are consistent with previous work that has found fewer meth lab seizures in Mississippi after enactment (Cunningham et al., 2012). This prior study used an interrupted time series design that compared lab seizure trends before and after the policy change. The synthetic control method we use allows us to exploit the panel nature of state data. The synthetic control

\footnotetext{
${ }^{3}$ More formally, we have also computed the ratio of the root mean squared prediction error (RMSPE) in the posttreatment period to the pre-treatment period for each state. This ratio is highest for Mississippi compared to all placebo treatment states indicating statistical significance at the $\frac{1}{50}=0.02 \%$ level.
} 
algorithm constructs a control state that closely matches the trends in Mississippi in the pretreatment period, but allows us to compare outcomes in post-prescription requirement Mississippi to a synthetic version of Mississippi that had not enacted a prescription requirement. While Cunningham et al. (2012) also compute interrupted time series for selected nearby states, the method used does not provide for explicit statistical tests of a difference in impacts between Mississippi and the selected control states. When combined with permutation testing, the synthetic control method allows us to confirm the trend in Mississippi was statistically different from posttreatment trends in other states.

Our second new contribution was to examine the impacts of Mississippi's prescription requirement on prices using STRIDE data. Prescription-requirements restrict access to precursor inputs used in the production of methamphetamine and therefore may have some impact on the quantity supplied in the marketplace. Given that demand for meth changes very little with price (Cunningham and Finlay, 2015), our failure to find evidence for higher prices suggests that the disruptive effects of prescription-only legislation on meth availability is quite small. This may likely be due to international imports being readily available to displace domestic producers.

The principal limitations of our analysis were the lack of direct data on meth production and use. Since we did not have data on meth production, we relied on the number of law enforcement seizures as a proxy. While lab seizures are likely partly a function of local meth production activity, they are also a function of law enforcement effort levels. If law enforcement in Mississippi relaxed efforts to seize meth labs following enactment of the prescription law, it may have contributed to use detecting spurious impacts. Likewise, without direct data on meth use, or indirect data on health care encounters related to meth use, we were forced to rely on price estimates. We would have been unable to detect any impact on small subsistence manufacturers that did not participate in the meth market after precursors became more difficult to obtain through the Mississippi law. Additionally, prices may be a poor indication of the impact of state-specific meth use if transport from other states or countries is relatively low-cost.

The failure of the prescription only requirements for precursors to influence prices is likely partly due to the size of the meth labs seized relative to the amount imported from unaffected regions, especially Mexico. The labs with capacity less than 2 ounces that we focused on in this analysis produce at most 200 doses per batch (Sexton et al., 2006). Interrupting the production 
cycles of these small labs may have an insufficient effect on total volume of meth production to influence the supply or price of the product in the market. Further, as roughly $80 \%$ of domestic meth consumption comes from Mexican imports ([US NDIC] United States National Drug Intelligence Center, 2010), even large domestic producers have a limited impact on supply of meth in the United States.

The beneficial impact of Mississippi's law was likely focused on the social costs associated purely with small lab production technologies — primarily reduced cleanup and environmental costs (\$29 million nationwide in 2005), and any associated chemical burns or other injuries or death that may result from lab mishaps (\$32 million nationwide in 2005). This suggests that the benefits of prescription-only requirements are only a small portion of the total social costs of meth abuse (\$23 billion nationwide in 2005)(Nicosia et al., 2009). This is consistent with prior work that has found regulations targeting small-scale producers in California in the 1990s had no impact on meth-related hospital admissions (Cunningham and Liu, 2003).

Our study offers some guidance in the policy debate regarding the efficacy of prescriptiononly legislation. While effective at reducing small-scale domestic production, prescription-only restrictions for meth precursors appear to have no impact on price and thus likely a limited impact on drug availability. This may indicate the law had little impact on drug usage and social costs related to drug usage. While our comparative case study approach is limited to identifying the impact of Mississippi's prescription-only law on meth markets, the insights we learn may have some value for precursor control more generally. Our analysis points to the limited efficacy of these interventions when interventions are pursued on a state-by-state basis. When markets are connected by global supply chains, localized interventions are relatively ineffective at shifting the supply curve. A much larger intervention at the federal level, such as was pursued with the Combat Methamphetamine Epidemic Act of 2005, may have more success at disrupting markets, given the sizable reduction in supply that accompanies large-scale interventions. Though, even nationlevel interventions may have limited impact given the international nature of meth production. The presence of uncontrolled sectors, such as the production system in Mexico, will always mean that substitution may occur. Policy-makers considering the state-by-state approach for meth or other illegal drugs should be aware of the limitations of regulating only local production.

But our study also highlights opportunities. Where localized interventions fail, international 
efforts may succeed insofar as international efforts can remove unregulated sectors. Removing unregulated sectors may be key to precursor control's future success. 


\section{References}

Abadie, Alberto, Alexis Diamond, and Jens Hainmueller. 2010. Synthetic Control Methods for Comparative Case Studies: Estimating the Effect of California's Tobacco Control Program. Journal of the American Statistical Association 105(490): 493-505.

http://pubs.amstat.org/doi/abs/10.1198/jasa.2009.ap08746

2011. Synth: Stata Module to Implement Synthetic Control Methods for Comparative Case Studies. Software published at Statistical Software Components.

http://ideas.repec.org/c/boc/bocode/s457334.html

Abadie, Alberto and Javier Gardeazabal. 2003. The Economic Costs of Conflict: A Case Study of the Basque Country. American Economic Review 93(1): 113-32.

http://dx.doi.org/10.1257/000282803321455188

Arkes, Jeremy, Rosalie Liccardo Pacula, Susan M. Paddock, Jonathan P. Caulkins, and Peter Reuter. 2004. Technical Report for the Price and Purity of Illicit Drugs through 2003. Santa Monica, CA: Rand Corporation.

https://www.ncjrs.gov/ondcppubs/publications/pdf/price_purity_tech_rpt.pdf

Chew Ng, Rilene A., Michael C. Samuel, Terrence Lo, Kyle T. Bernstein, Getahun Aynalem, Jeffrey D. Klausner, and Gail Bolan. 2012. Sex, Drugs (Methamphetamines), and the Internet: Increasing Syphilis Among Men Who Have Sex With Men in California, 2004-2008. American Journal of Public Health 103(8): 1450-56.

http://dx.doi.org/10.2105/AJPH.2012.300808

Cunningham, James K., Russell C. Callaghan, Daoqin Tong, Lon-Mu Liu, Hsiao-Yun Lie, and William J. Lattyak. 2012. Changing Over-the-Counter Ephedrine and Pseudoephedrine Products to Prescription Only: Impacts on Methamphetamine Clandestine Laboratory Seizures. Drug and Alcohol Dependence 126(1-2): 55-64.

http://dx.doi.org/10.1016/j.drugalcdep.2012.04.011

Cunningham, James K. and Lon-Mu Liu. 2003. Impacts of Federal Ephedrine and Pseudoephedrine Regulations on Methamphetamine-Related Hospital Admissions. Addiction 98(9): 
1229-37.

http://dx.doi.org/10.1046/j.1360-0443.2003.00450.x

Cunningham, Scott and Keith Finlay. 2015. Identifying Demand Responses to Illegal Drug Supply Interdictions. Revision resubmitted to Health Economics.

http://ideas.repec.org/p/tul/wpaper/1312.html

Dobkin, Carlos and Nancy Nicosia. 2009. The War on Drugs: Methamphetamine, Public Health, and Crime. American Economic Review 99(1): 324-49.

http://www. aeaweb.org/articles.php?doi=10.1257/aer.99.1.324

Dobkin, Carlos, Nancy Nicosia, and Matthew Weinberg. 2014. Are Supply-Side Drug Control Efforts Effective? Evaluating OTC Regulations Targeting Methamphetamine Precursors. Journal of Public Economics 120: 48-61.

http://www.sciencedirect.com/science/article/pii/s0047272714001789

Gonzales, Rachel, Larissa Mooney, and Richard A. Rawson. 2010. The Methamphetamine Problem in the United States. Annual Review of Public Health 31(1): 385-98.

http://www.annualreviews.org/doi/abs/10.1146/annurev.publhealth.012809.103600

Kushel, Margot B., Judith A. Hahn, Jennifer L. Evans, David R. Bangsberg, and Andrew R. Moss. 2005. Revolving Doors: Imprisonment among the Homeless and Marginally Housed Population. American Journal of Public Health 95(10): 1747-52.

http://dx.doi.org/10.2105/AJPH.2005.065094

Nicosia, Nancy, Rosalie Liccardo Pacula, Beau Kilmer, Russell Lundberg, and James Chiesa. 2009. The Economic Cost of Methamphetamine Use in the United States, 2005. Santa Monica, CA: Rand Corporation.

http: //www.rand.org/pubs/monographs/MG829

[SAMHSA] Substance Abuse and Mental Health Services Administration. 2014. Results from the 2013 National Survey on Drug Use and Health: Summary of National Findings. NSDUH Series H-48, HHS Publication No. (SMA) 14-4863. 
Sexton, Rocky L., Robert G. Carlson, Carl G. Leukefeld, and Brenda M. Booth. 2006. Methamphetamine Use and Adverse Consequences in the Rural Southern United States: An Ethnographic Overview. Journal of Psychoactive Drugs 38(Supplement 3): 393-404.

http://dx.doi.org/10.1080/02791072.2006.10400603

Shaw, Souradet Y., Lena Shah, Ann M. Jolly, and John L. Wylie. 2008. Identifying Heterogeneity among Injection Drug Users: A Cluster Analysis Approach. American Journal of Public Health 98(8): 1430-37.

http://dx.doi.org/10.2105/AJPH.2007.120741

[US DEA] United States Drug Enforcement Administration. 2013. National Drug Threat Assessment. Product Number DEA-NWW-DIR-017-13.

http://www.justice.gov/dea/resource-center/DIR-017-13\%20NDTA\%20Summary\%20final.pdf

[US NDIC] United States National Drug Intelligence Center. 2010. National Methamphetamine Threat Assessment. Product Number 2010-Q0317-004.

http://s3.amazonaws.com/nytdocs/docs/374/374.pdf 
Table 1: Predictor balance: United States controls vs. Mississippi vs. Synthetic Control Meth Lab Incidents

\begin{tabular}{|c|c|c|c|}
\hline Variable & United States & Mississippi & Synthetic \\
\hline Mean meth lab seizures $(11 / 2009,12 / 2009$ and $1 / 2010)$ & 19.99 & 78.67 & 78.52 \\
\hline Mean legalized medical marijuana & 0.20 & 0 & 0.005 \\
\hline Mean $\ln ($ cigarette tax $)$ & -4.87 & -6.00 & -5.82 \\
\hline Mean $\ln ($ state unemployment rate) & 1.70 & 1.92 & 1.81 \\
\hline Mean $\ln$ (number of people on Supplemental Nutrition Assistance Program) & 5.73 & 5.94 & 5.97 \\
\hline Mean Population $15-49$ year olds & $2,942.14$ & $1,426.95$ & $1,977.92$ \\
\hline
\end{tabular}

Notes: Means for each variable used to generate weights for synthetic Mississippi in the lab seizure series are shown in Table 1. The first column shows the average of each variable in the United States. The second shows the average in Mississippi. The third column shows the average in the constructed synthetic Mississippi. 
Table 2: Predictor balance: United States controls vs. Mississippi vs. Synthetic Control Meth Lab Incidents

\begin{tabular}{|c|c|c|c|}
\hline Variable & United States & Mississippi & Synthetic \\
\hline Mean Meth price (2010q1) & 84.52 & 71.79 & 73.61 \\
\hline Mean Meth price (2009q4) & 84.21 & 69.13 & 80.19 \\
\hline Mean Meth price (2009q2) & 92.58 & 72.27 & 83.09 \\
\hline Mean Meth price (2008q4) & 98.82 & 78.87 & 88.69 \\
\hline Mean Meth price (2008q1) & 92.30 & 126.13 & 120.49 \\
\hline Mean Meth price $(2007 q 1-2007 q 2)$ & 19.99 & 76.31 & 68.94 \\
\hline Mean legalized medical marijuana & 0.24 & 0 & 0.17 \\
\hline Mean $\ln ($ cigarette tax $)$ & -0.00 & -1.26 & -0.25 \\
\hline Mean $\ln ($ state unemployment rate) & 1.90 & 2.03 & 1.87 \\
\hline Mean $\ln$ (number of people on Supplemental Nutrition Assistance Program) & 6.13 & 6.14 & 6.40 \\
\hline Mean Population $15-49$ year olds & $3,180.22$ & $1,415.73$ & $3,876.73$ \\
\hline
\end{tabular}

Notes: Means for each variable used to generate weights for synthetic Mississippi in the meth price series are shown in Table 1. The first column shows the average of each variable in the United States. The second shows the average in Mississippi. The third column shows the average in the constructed synthetic Mississippi. 


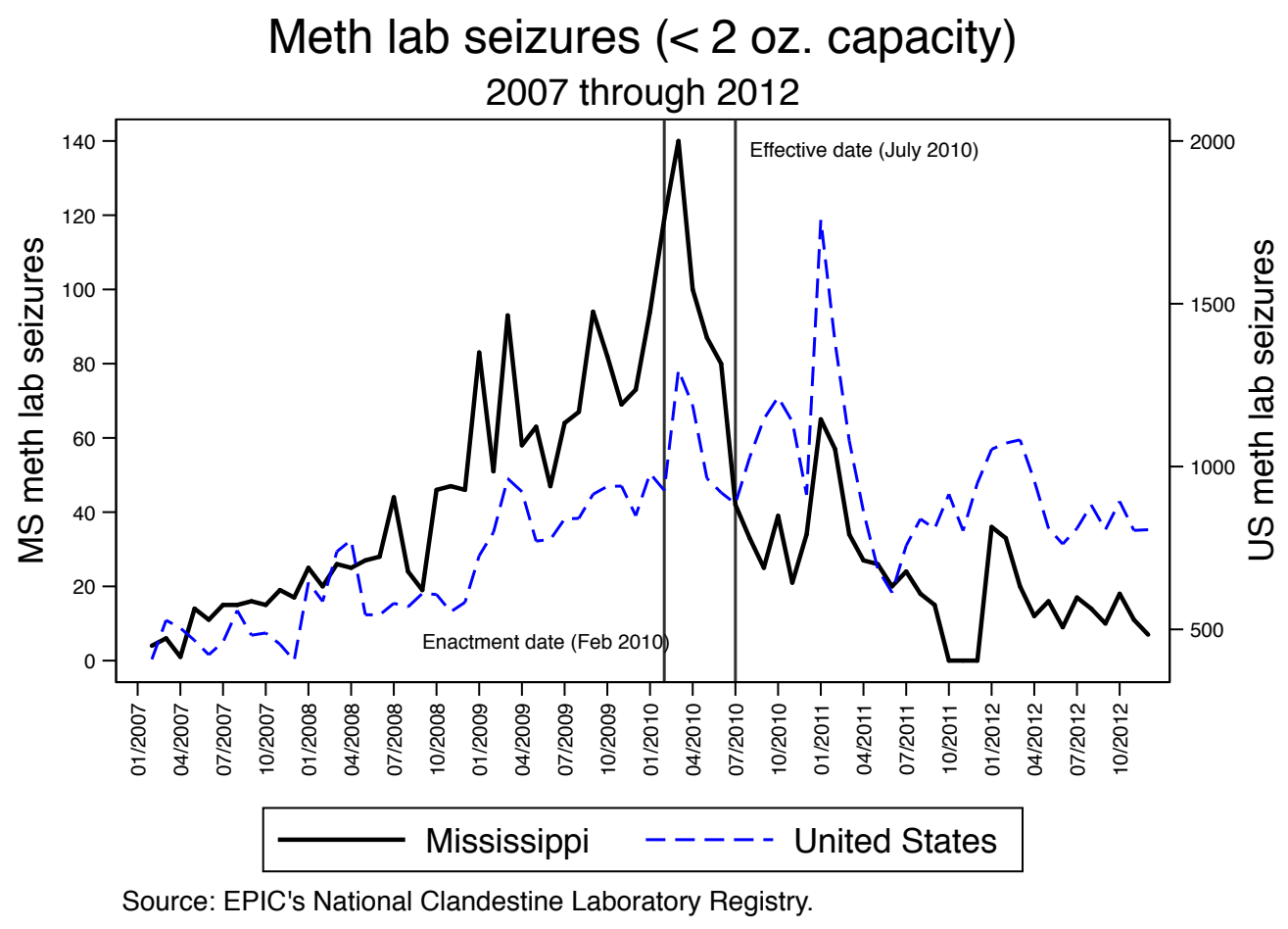

Figure 1: US (right axis) vs. Mississippi (left axis) methamphetamine clandestine lab seizures with under $2 \mathrm{oz}$. production capacity per production cycle. The first vertical bar represents the date Mississippi enacted prescription-only requirements and the second vertical bar represents its effective date. 

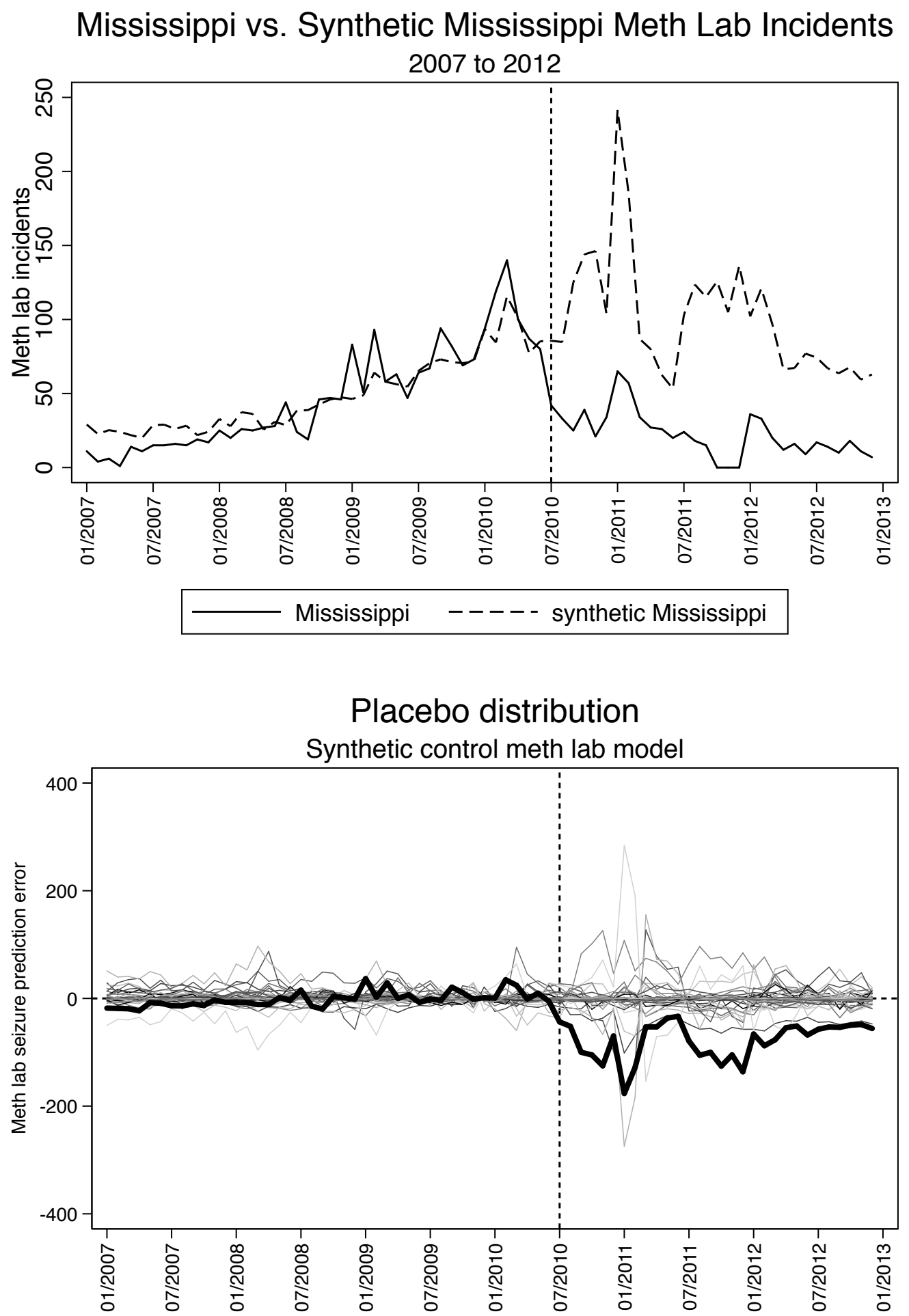

Figure 2: Top panel: Methamphetamine lab seizures under 2 oz in Mississippi and synthetic Mississippi. Bottom panel: Distribution of prediction error in small methamphetamine lab seizures from all placebo estimates (grey lines) and Mississippi (dark line). 


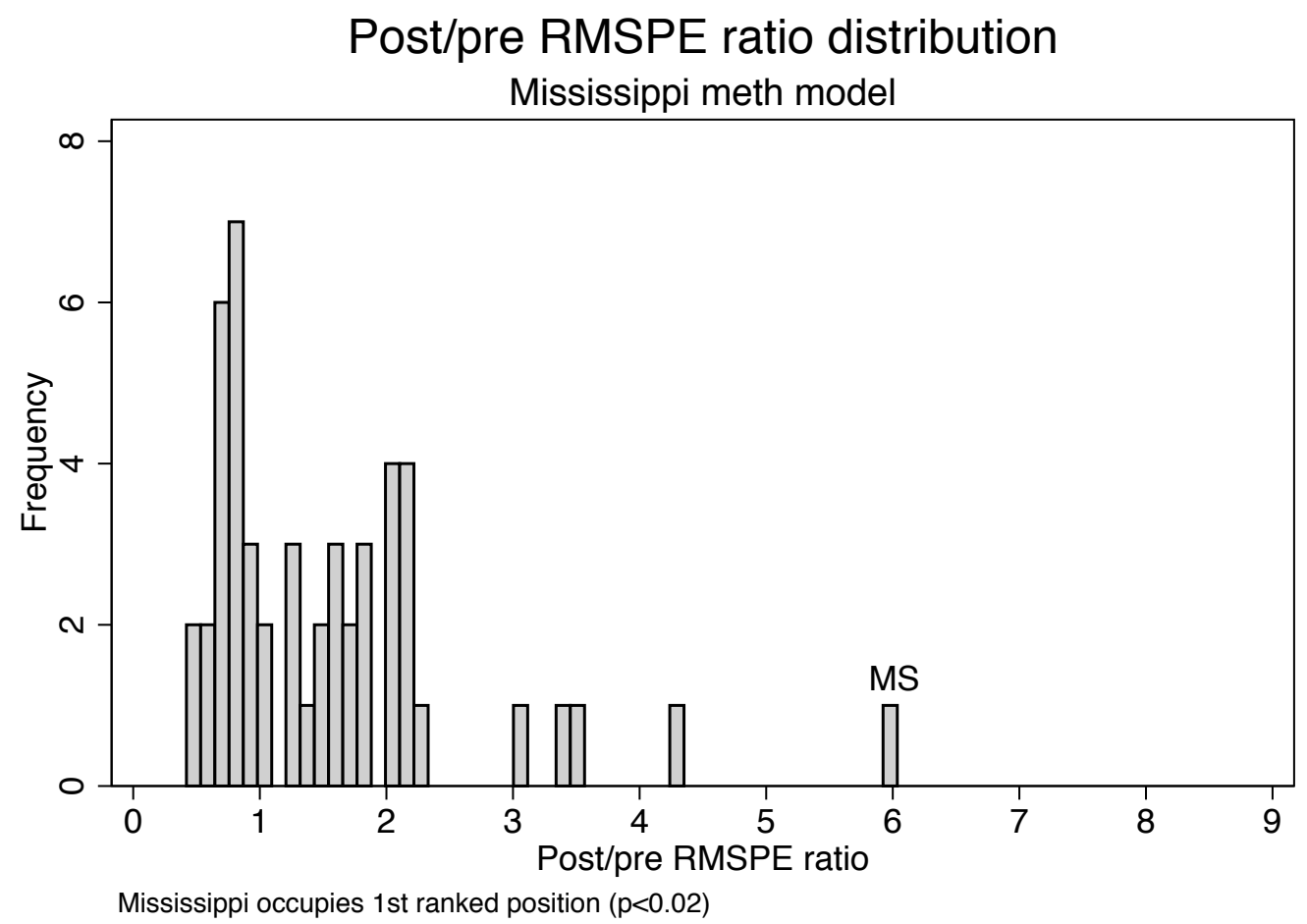

Figure 3: Histogram of all states' ratio of post-root mean squared prediction error (RMSPE) to pre-RMSPE for the Mississippi methamphetamine lab synthetic control model. 


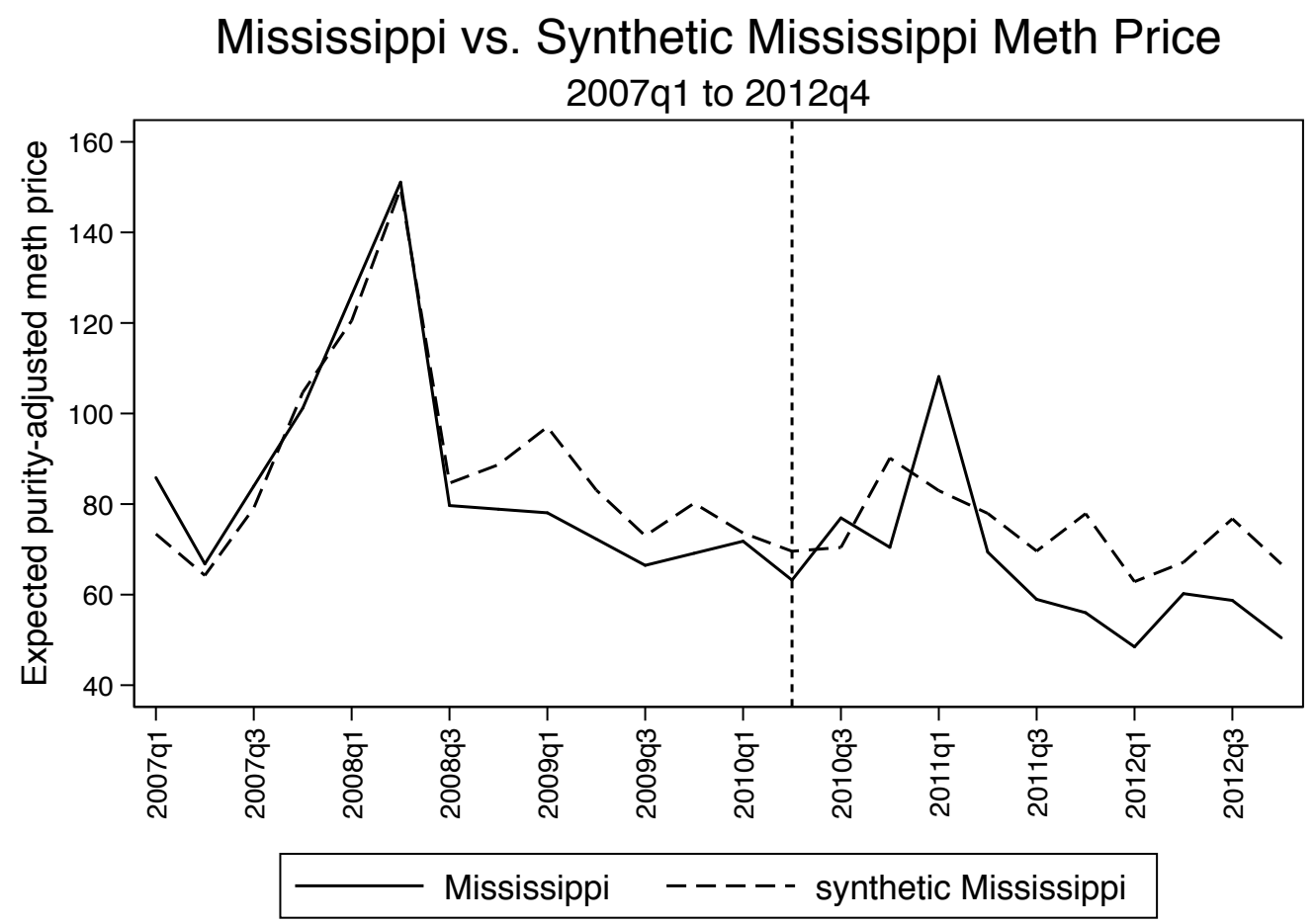

Placebo distribution

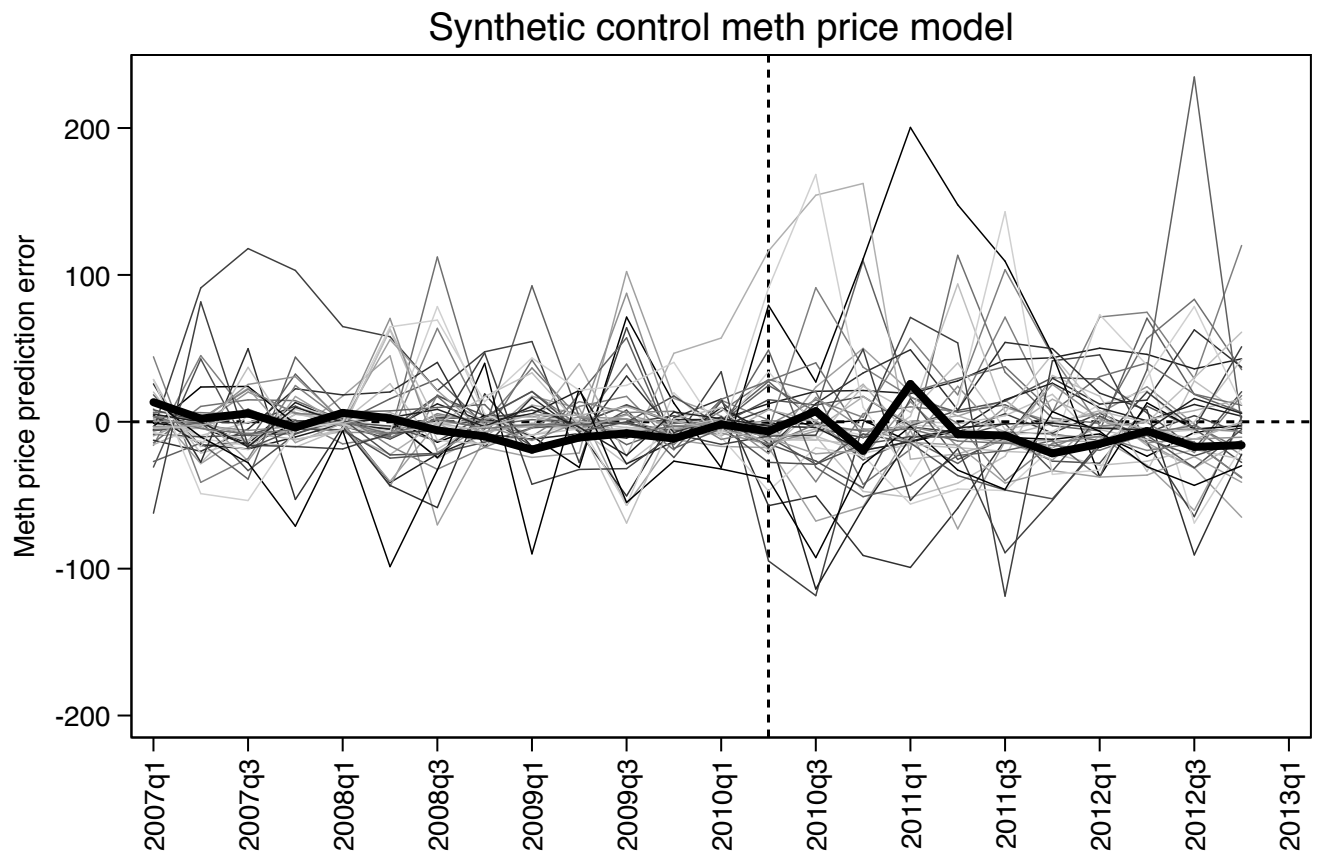

Figure 4: Top panel: Methamphetamine price in Mississippi and synthetic Mississippi. Bottom panel: Distribution of prediction error in methamphetamine price from all placebo estimates (grey lines) and Mississippi (dark line). 